Communications in Physics, Vol. 22, No. 4 (2012), pp. 349-355

\title{
INFLUENCE OF TIME DEPENDENCE OF DYNAMIC LASER PARAMETER ON THE THREE MODES RANDOM LASER OPERATION
}

\author{
DINH VAN HOANG AND LE NGOC ANH \\ Hanoi National University \\ NGUYEN VAN PHU \\ Vinh University
}

\begin{abstract}
In this report we demonstrate the influence of the photon density on the operation of a three modes random laser when the gain coefficients of modes depending on time. Supposing gain coefficients had Gaussian profile and using Matlab language, we have solved the basic equations describing the operation of the three modes random laser. The received results give us more real knowledge about the appearance of modes in random laser.
\end{abstract}

\section{INTRODUCTION}

Random laser appeared in the early 1990's since Lawandy et al. [1] reported stimulated emission from dye solution which contains micro-particles. After this report, many experimental and theoretical studies on random laser have been published [2-8]. In fact, the mechanism of light amplification in disordered media up to now is not clear. Therefore one has proposed hypothesis, supposition and realized many experimental or theoretical studies for explaining the operation of random laser.

With this aim, in the article [9] we have studied characteristics of modes generated by two and three modes random laser. The transformation of these mode characteristics depends mainly on the change of laser parameters like the gain and loss coefficients or the field coupling and photon hopping coefficients. However, in [9] that transformation corresponded only to the variation of the values of coefficients indicated above, while each coefficient, in fact, depended on time in the process of laser operation, and this time dependence was not disscussed.

Starting from this situation, in this work we examine the case in which the gain coefficient depends on time and we hope that the received results will give us a general and nearly real scenario about mechanism of random laser.

\section{BASIC EQUATIONS AND METHOD OF RESOLUTION}

Supposing random laser generated three modes with photon densities $\mathrm{n}_{1}, \mathrm{n}_{2}, \mathrm{n}_{3}$, respectively, and where $\mathrm{n}_{2}$ belongs to the middle mode. Following [4], equations describing the variation on time of modes are written, as follows:

$$
\frac{d n_{1}}{d t}=\alpha_{1} n_{1}-\beta_{1} n_{1}^{2}-\theta_{12} n_{1} n_{2}+\gamma_{12} n_{2}
$$




$$
\begin{gathered}
\frac{d n_{2}}{d t}=\alpha_{2} n_{2}-\beta_{2} n_{2}^{2}-\left(\theta_{21} n_{1}+\theta_{23} n_{3}\right) n_{2}+\gamma_{21} n_{1}+\gamma_{23} n_{3} \\
\frac{d n_{3}}{d t}=\alpha_{3} n_{3}-\beta_{3} n_{3}^{2}-\theta_{32} n_{2} n_{3}+\gamma_{32} n_{2}
\end{gathered}
$$

Here $\alpha_{i}, \beta_{i}(i=1,2,3)$ are gain and loss coefficients and $\theta_{i j}, \gamma_{i j}(j=1,2,3)$ are field coupling and photon hopping coefficients, respectively.

In case the gain coefficients depend on time, we choose for $\alpha_{i}$ :

$$
\alpha_{i}=\alpha_{0 i} e^{-\Delta T t^{2}}
$$

this $\alpha_{i}$ is corresponding to Gaussian profile of generated pulse mode.

For solving this system of equations with $\alpha_{i}$ following (4), we use numerical method on the base of Matlab language. Initial conditions are given:

$$
\begin{array}{r}
n_{1}(0)=n_{2}(0)=n_{3}(0)=0.2(\text { in a.u }) \\
\Delta T_{1}=\Delta T_{2}=\Delta T_{3}=2(\mathrm{~ns})
\end{array}
$$

Other values of coefficients $\alpha_{0 i}, \beta_{i}, \theta_{i j}, \gamma_{i j}$ are given in:

$$
\begin{aligned}
& \alpha_{01}=0.9 \mathrm{~s}^{-1} ; \beta_{1}=0.4 \mathrm{~cm}^{3} \cdot \mathrm{s}^{-1} ; \theta_{12}=\theta_{21}=0.4 \mathrm{~cm}^{3} . \mathrm{s}^{-1} ; \gamma_{12}=0.8 \mathrm{~s}^{-1} . \\
& \alpha_{02}=1.3 \mathrm{~s}^{-1} ; \beta_{2}=0.3 \mathrm{~cm}^{3} \cdot \mathrm{s}^{-1} ; \theta_{23}=0.4 \mathrm{~cm}^{3} \cdot \mathrm{s}^{-1} ; \gamma_{21}=\gamma_{23}=0.7 \mathrm{~s}^{-1} . \\
& \alpha_{03}=0.9 \mathrm{~s}^{-1} ; \beta_{3}=0.5 \mathrm{~cm}^{3} . \mathrm{s}^{-1} ; \theta_{32}=0.4 \mathrm{~cm}^{3} . \mathrm{s}^{-1} ; \gamma_{32}=0.8 \mathrm{~s}^{-1} .
\end{aligned}
$$

The distribution of mode photon densities $n_{i}(t)$ is presented in Fig. 1

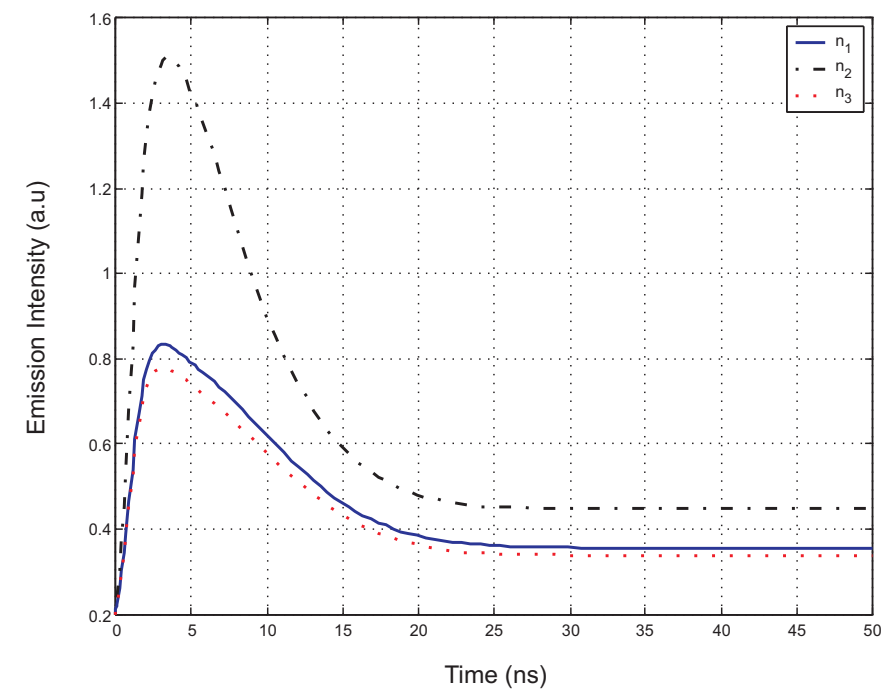

Fig. 1. The curves of $n_{i}(t)$ versus time.

From Fig. 1, we see that the profile of curves $n_{i}(t)$ in case the gain coefficient depending on time has same form as the gain coefficients are constant. 
For examining the evaluation of photon density $n_{i}(t)$ when the profile of gain coefficients $\alpha_{i}$ varies, we note the three parameters of these curves as following:

The $\Delta \omega_{i}$ is the pulse width of the $i^{t h}$ mode.

The $I_{i}^{\max }$ is the maximum photon density of $i^{t h}$ mode.

The $T_{i}^{\max }$ is the time for reaching maximum photon density of $i^{\text {th }}$ mode.

\section{INFLUENCE OF THE VARIATION OF GAIN COEFFICIENTS}

\section{III.1. The influence of $\Delta T$}

Starting with the formula (4), we can vary one of two parameters $\Delta T$ and $\alpha_{0 i}$. Giving different values of $\Delta T$ and remaining invariable all values of coefficients presented above, we can receive curves $n_{i}(t)$ presented in figures 2, 3 and 4 . From these figures we determine pulses mode parameters. The results are given in Table 1.

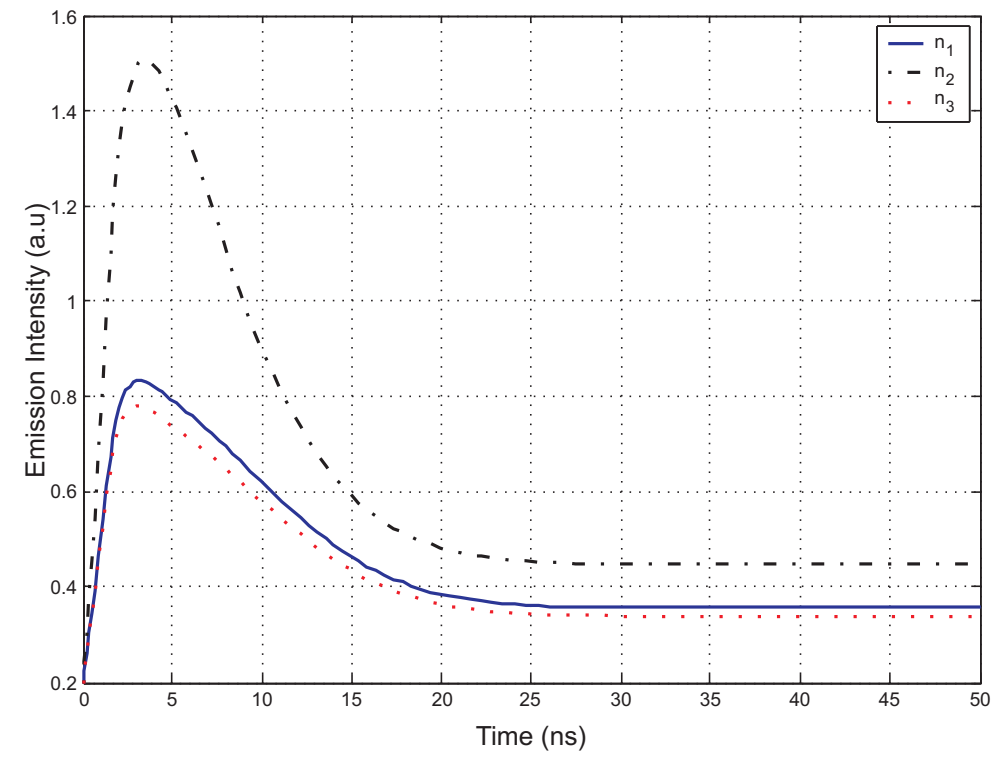

Fig. 2. The curves of $n_{i}(t)$ with $\Delta T=2$ ns.

Table 1. Computation results of the influence of $\Delta \mathrm{T}$ on the characteristics of modes of random laser

\begin{tabular}{|c|c|c|c|c|c|c|c|c|c|}
\hline $\begin{array}{l}\Delta T \\
(\mathrm{~ns})\end{array}$ & $\begin{array}{r}T_{1}^{\max } \\
\text { (ns) }\end{array}$ & $\begin{array}{l}I_{1}^{\max } \\
\text { (a.u) }\end{array}$ & $\begin{array}{r}\Delta \omega_{1}(\mathrm{~ns}) \\
(\mathrm{ns})\end{array}$ & $\begin{array}{l}T_{2}^{\max } \\
\text { (ns) }\end{array}$ & $\begin{array}{l}I_{2}^{\max } \\
\text { (a.u) }\end{array}$ & $\begin{array}{l}\Delta \omega_{2} \\
(\mathrm{~ns})\end{array}$ & $\begin{array}{c}T_{3}^{\max } \\
(\mathrm{ns})\end{array}$ & $\begin{array}{l}I_{3}^{\max } \\
(\mathrm{a} . \mathrm{u})\end{array}$ & $\begin{array}{l}\text { (ns) } \\
\text { (ns) }\end{array}$ \\
\hline 1 & 2.3848 & 0.6927 & 4.3548 & 2.2465 & 1.1050 & 4.8378 & 2.2465 & 0.6547 & 4.0092 \\
\hline 2 & 3.4101 & 0.8284 & 9.4009 & 3.4908 & 1.5038 & 9.5391 & 3.2258 & 0.7751 & 9.2166 \\
\hline 3 & 3.9174 & 0.8526 & 26.7281 & 6.1060 & 1.6854 & 29.9539 & 3.8018 & 0.7965 & 26.0368 \\
\hline 4 & 6.4516 & 0.8620 & 94.0092 & 10.0230 & 1.7556 & 97.2458 & 3.8018 & 0.7965 & 87.5576 \\
\hline 6 & & & $\rightarrow \infty$ & & & $\rightarrow \infty$ & & & $\rightarrow \infty$ \\
\hline
\end{tabular}




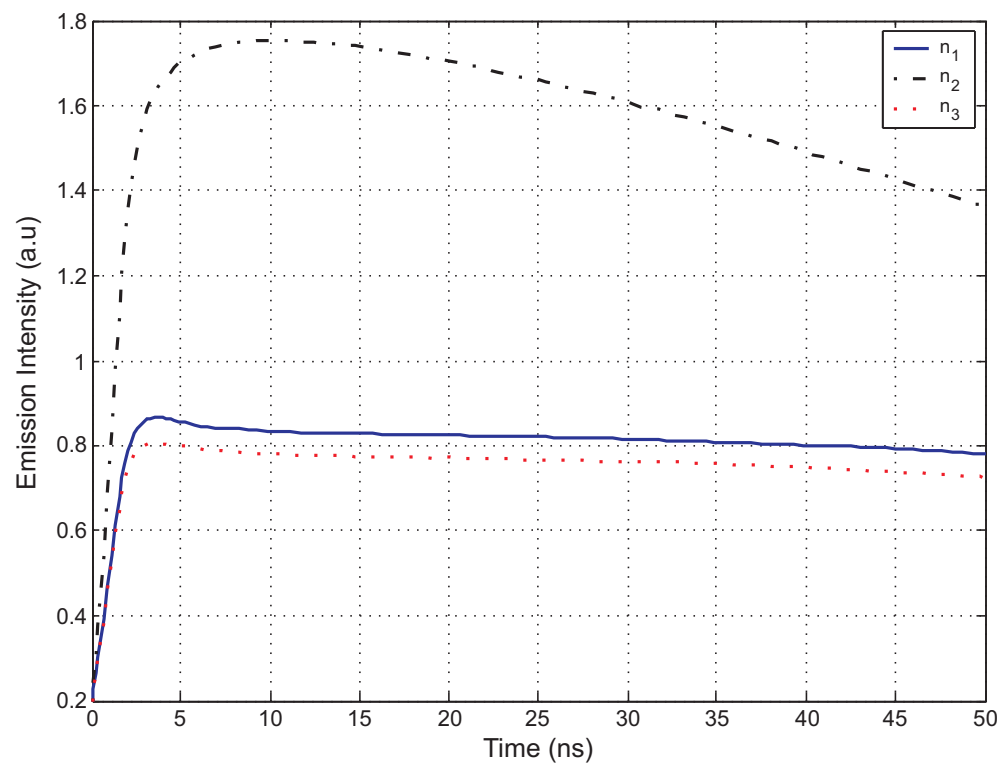

Fig. 3. The curves of $n_{i}(t)$ with $\Delta T=4 \mathrm{~ns}$.

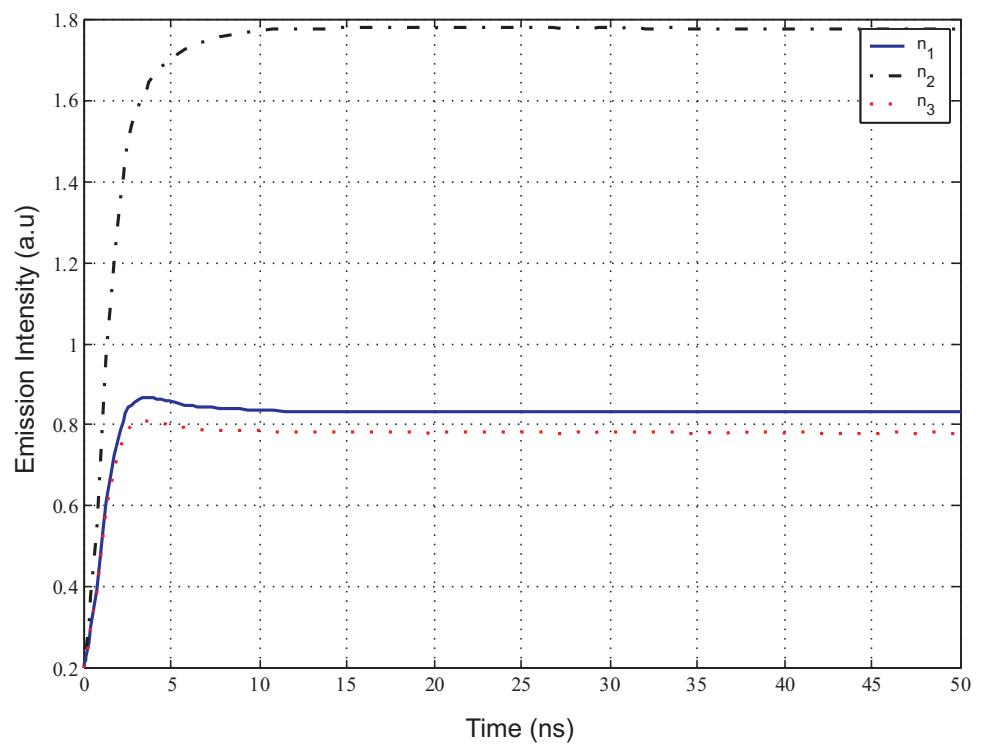

Fig. 4. The curves of $n_{i}(t)$ with $\Delta T=6$ ns.

From received results, we see that: The more the values of $\Delta T$ are small, the quickly the time for reaching maximum photon density of mode attains and analogously the smaller the values of maximum photon density and pulse width have. 


\section{III.2. Influence of initial values of gain coefficients $\alpha_{0 i}$}

By the same method of calculation, here we change in turn the values of $\alpha_{0 i}(i=1$, $2,3)$. Obtained results are given in Table 2, 3, 4 .

Table 2. Computation results of the influence of $\alpha_{01}$ on the characteristics of modes of random laser

\begin{tabular}{|c|c|c|c|c|c|c|c|c|c|}
\hline $\begin{array}{c}\alpha_{01} \\
\left(\mathrm{~s}^{-1}\right)\end{array}$ & $\begin{array}{r}T_{1}^{\max } \\
(\mathrm{ns})\end{array}$ & $\begin{array}{l}I_{1}^{\max } \\
\text { (a.u) }\end{array}$ & $\begin{array}{l}\Delta \omega_{1} \\
(\mathrm{~ns})\end{array}$ & $\begin{array}{c}T_{2}^{\max } \\
T_{2}^{\max }(\mathrm{ns})\end{array}$ & $\begin{array}{r}I_{2}^{\max } \\
I_{2}^{\max }(\mathrm{a} \cdot \mathrm{u})\end{array}$ & $\begin{array}{l}\Delta \omega_{2} \\
(\mathrm{~ns})\end{array}$ & $\begin{array}{r}T_{3}^{\max } \\
\text { (ns) }\end{array}$ & $\begin{array}{c}\left.I_{3}^{\max }\right) \\
(\mathrm{a} . \mathrm{u})\end{array}$ & $\begin{array}{l}\Delta \omega_{3} \\
(\mathrm{~ns})\end{array}$ \\
\hline 0.1 & 4.0438 & 0.4658 & 7.8111 & 3.9747 & 1.8000 & 8.7788 & 2.6613 & 0.7553 & 8.8479 \\
\hline 0.3 & 3.9747 & 0.5205 & 8.9171 & 3.9055 & 1.7509 & 9.0553 & 2.7304 & 0.7591 & 9.2627 \\
\hline 0.5 & 3.2834 & 0.5906 & 9.1244 & 3.8364 & 1.6854 & 9.3318 & 2.8687 & 0.7684 & 9.4700 \\
\hline 0.7 & 3.2143 & 0.6936 & 9.7465 & 3.7673 & $\overline{1.6012}$ & 9.8847 & 2.9378 & 0.7778 & 10.0921 \\
\hline 0.9 & 3.1452 & 0.8365 & 10.3686 & 3.4908 & 1.5079 & 10.1612 & 3.0530 & 0.7833 & 10.1785 \\
\hline 1.1 & 3.3525 & 1.0289 & 10.9908 & 3.0069 & 1.4015 & 10.4378 & 3.2834 & 0.7956 & 10.2304 \\
\hline 1.3 & 3.5599 & 1.2950 & 11.6820 & 2.7304 & 1.2991 & 11.3364 & 3.6290 & 0.8120 & 10.7834 \\
\hline 1.5 & 3.9747 & 1.6620 & 10.7834 & 2.5230 & 1.2082 & 9.6774 & 3.9747 & 0.8339 & 9.3318 \\
\hline
\end{tabular}

Table 3. The influence of $\alpha_{02}$ on the characteristics of modes of random laser

\begin{tabular}{|c|c|c|c|c|c|c|c|c|c|}
\hline $\begin{array}{r}\alpha_{02} \\
\left(\mathrm{~s}^{-1}\right) \\
\end{array}$ & $\begin{array}{r}T_{1}^{\max } \\
\text { (ns) }\end{array}$ & $\begin{array}{l}I_{1}^{\max } \\
(\mathrm{a} . \mathrm{u})\end{array}$ & $\begin{array}{l}\Delta \omega_{1} \\
(\mathrm{~ns})\end{array}$ & $\begin{array}{c}T_{2}^{\max } \\
\text { (ns) }\end{array}$ & $\begin{array}{l}I_{2}^{\max } \\
\text { (a.u) }\end{array}$ & $\begin{array}{l}\Delta \omega_{2} \\
(\mathrm{~ns})\end{array}$ & $\begin{array}{c}T_{3}^{\max } \\
\text { (ns) }\end{array}$ & $\begin{array}{l}I_{3}^{\max } \\
(\mathrm{a} . \mathrm{u})\end{array}$ & $\begin{array}{r}\omega_{3} \\
(\mathrm{~ns})\end{array}$ \\
\hline 0.2 & 2.8687 & 0.8105 & 9.6774 & 3.9055 & 1.7556 & 8.9171 & 3.6982 & 0.4784 & 7.6037 \\
\hline 0.4 & 3.0069 & 0.8199 & 9.8848 & 3.8364 & 1.6947 & 9.2627 & 3.5599 & 0.5345 & 8.2949 \\
\hline 0.6 & 3.0760 & 0.8246 & 9.9539 & 3.7673 & 1.6339 & 9.3318 & 3.4908 & 0.6140 & 9.3318 \\
\hline 0.8 & 3.1452 & 0.8325 & 10.2304 & 3.6290 & 1.5488 & 9.5318 & 2.9397 & 0.7178 & 10.0230 \\
\hline 1.0 & 3.3525 & 0.8447 & 10.3329 & 3.4217 & 1.4629 & 10.2304 & 3.0069 & 0.8570 & 10.6452 \\
\hline 1.2 & 3.4908 & 0.8611 & 10.6451 & 3.1452 & 1.3687 & 10.4378 & 3.1452 & 1.0412 & 10.0230 \\
\hline 1.4 & 3.8364 & 0.8816 & 10.9907 & 2.7304 & 1.2746 & 11.4746 & 3.2143 & 1.2827 & 10.0922 \\
\hline 1.6 & 4.1820 & 0.9102 & 11.6129 & 2.5230 & 1.1927 & 11.6820 & 3.4217 & 1.5898 & 10.2995 \\
\hline
\end{tabular}

Table 4. The influence of $\alpha_{03}$ on the characteristics of modes of random laser

\begin{tabular}{|c|c|c|c|c|c|c|c|c|c|}
\hline $\begin{array}{r}\alpha_{03} \\
\left(\mathrm{~s}^{-1}\right) \\
\end{array}$ & $\begin{array}{r}T_{1}^{\max } \\
(\mathrm{ns}) \\
\end{array}$ & $\begin{array}{l}I_{1}^{\max } \\
\text { (a.u) }\end{array}$ & $\begin{array}{l}\Delta \omega_{1} \\
(\mathrm{~ns})\end{array}$ & $\begin{array}{r}T_{2}^{\max } \\
(\mathrm{ns}) \\
\end{array}$ & $\begin{array}{l}I_{2}^{\max } \\
\text { (a.u) }\end{array}$ & $\begin{array}{l}\Delta \omega_{2} \\
(\mathrm{~ns})\end{array}$ & $\begin{array}{r}T_{3}^{\max } \\
(\mathrm{ns})\end{array}$ & $\begin{array}{l}I_{3}^{\max } \\
\text { (a.u) }\end{array}$ & $\begin{array}{r}\Delta \omega_{3} \\
(\mathrm{~ns})\end{array}$ \\
\hline 0.5 & 4.3894 & 1.1079 & 9.4009 & 3.1452 & 0.6898 & 9.2627 & 4.1820 & 0.9792 & 9.4009 \\
\hline 0.7 & 4.3203 & 1.0465 & 9.4700 & 3.1665 & 0.8096 & 9.5391 & 4.1129 & 0.9383 & 9.6774 \\
\hline 0.9 & 4.1820 & 0.9778 & 9.6082 & 3.1943 & 0.9731 & 9.7465 & 3.8364 & 0.8865 & 9.7466 \\
\hline 1.1 & 3.6982 & 0.9032 & 9.7330 & 3.2143 & 1.1965 & 9.8847 & 3.4908 & 0.8330 & 9.8157 \\
\hline 1.3 & 3.0760 & 0.8325 & 9.8848 & 3.4908 & 1.5038 & 9.8156 & 2.9378 & 0.7792 & 9.9539 \\
\hline 1.5 & 2.7304 & 0.7763 & 10.0230 & 3.6982 & 1.9289 & 9.8848 & 2.6613 & 0.7395 & 10.0230 \\
\hline 1.7 & 2.2465 & 0.7346 & 10.1613 & 3.7673 & 2.4598 & 10.0230 & 2.3848 & 0.7054 & 10.2304 \\
\hline 2.0 & 1.9700 & 0.6908 & 10.0231 & 3.6290 & 3.3823 & 9.8856 & 2.0392 & 0.6601 & 10.5069 \\
\hline
\end{tabular}


From tables 2, 3 and 4, we see:

- The variation of $\alpha_{01}$ and $\alpha_{03}$ give the same effect for the evaluation of pulse mode parameters $T_{i}^{\max }, I_{i}^{\max }, \Delta \omega_{i}$.

- When $\alpha_{02}$ augments, the photon density of $2^{\text {th }}$ mode increases quickly. This point demonstrates that the more value of $\alpha_{02}$ is large, the quicker the photon hopping from near modes to middle mode grows.

\section{CONCLUSIONS}

We have simulated the influence of the dynamic laser parameters (such as variation of gain coefficients) on the characteristics of three modes of random laser by rate equations. We demonstrate the influence of the photon density curves on the operation of a three modes random laser when the gain coefficients of modes depend on time. Especially, when the gain coefficient $\alpha_{0 i}$ of any mode becomes largest, this mode will be brought in relief and laser generating three modes becomes laser generating single mode.

The numerical method used here in the case of three modes random laser, will be applied completely for the case of multimode random laser.

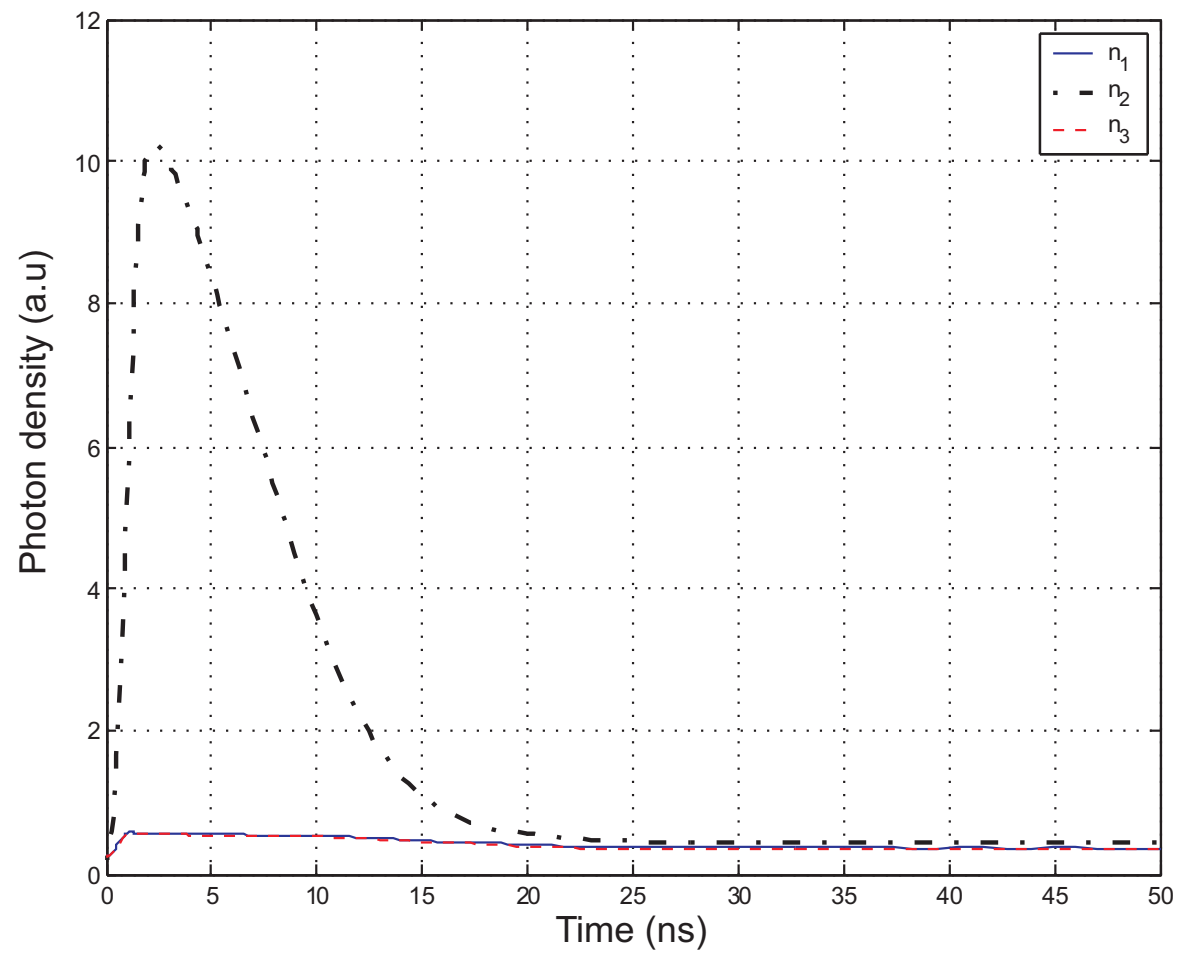

Fig. 5. The curves of $n_{i}(t)$ with $\alpha_{02}=4 \mathrm{~s}^{-1}$. 


\section{REFERENCES}

[1] N. M. Lawandy et al., Nature 368 (1994) 436.

[2] S. John and G. Pang, Phys. Rev. A54 (1996) 3642.

[3] G. A. Berger et al., Phys. Rev. E56 (1997) 6118.

[4] G. Zacharakis et al., Opt. Lett. 25 (2001) 923.

[5] A. L. Burin et al., Phys. Rev. Lett. 88 (2002) 3904.

[6] X. Jiang et al., Phys. Rev. B69 (2004) 104202.

[7] H. Cao et al., Appl. Phys. Lett. 73 (2005) 3656.

[8] D. V. Hoang, M. H. Hanh, VNU J. of Science Maths-Phys. 23(3) (2007) 139.

[9] Dinh Van Hoang, Nguyen Thi Phuong, Nguyen Van Phu, Computational Methods in Science and Technology, Special Issue 2, 47-53, Poland (2010).

Received 25 April 2012. 